\title{
The Structure of Phenotypic Personality Traits
}

\author{
Lewis R. Goldberg
}

This personal historical article traces the development of the Big-Five factor structure, whose growing acceptance by personality researchers has profoundly influenced the scientific study of individual differences. The roots of this taxonomy lie in the lexical hypothesis and the insights of Sir Francis Galton, the prescience of $L$. L. Thurstone, the legacy of Raymond B. Cattell, and the seminal analyses of Tupes and Christal. Paradoxically, the present popularity of this model owes much to its many critics, each of whom tried to replace it, but failed. In reaction, there have been a number of attempts to assimilate other models into the five-factor structure. Lately, some practical implications of the emerging consensus can be seen in such contexts as personnel selection and classification.

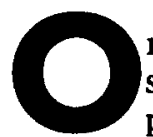
nce upon a time, we had no personalities (Mischel, 1968). Fortunately times change, and the past decade has witnessed an electrifying burst of interest in the most fundamental problem of the fieldthe search for a scientifically compelling taxonomy of personality traits. More importantly, the beginning of a consensus is emerging about the general framework of such a taxonomic representation. As a consequence, the scientific study of personality dispositions, which had been cast into the doldrums in the 1970s, is again an intellectually vigorous enterprise poised on the brink of a solution to a scientific problem whose roots extend back at least to Aristotle.

\section{The Lexical Hypothesis}

Sir Francis Galton may have been among the first scientists to recognize explicitly the fundamental "lexical hypothesis"-namely, that the most important individual differences in human transactions will come to be encoded as single terms in some or all of the world's languages. Moreover, Galton (1884) was certainly one of the first scientists to consult a dictionary as a means of estimating the number of personality-descriptive terms in the lexicon and to appreciate the extent to which trait terms share aspects of their meanings. Galton's estimate of the number of personality-related terms in English was later sharpened empirically, first by Allport and Odbert (1936), who culled such terms from the second edition of Webster's Unabridged Dictionary, and later by Norman (1967), who supplemented the earlier list with terms from the third edition. Galton's insight concerning the relations among personality terms has been mirrored in efforts by later investigators to discover the nature of those relations, so as to construct a structural representation of personality descriptors.
One of the first of these investigators was L. L. Thurstone, a pioneer in the development of factor analysis; the report of his initial findings reads today with almost haunting clairvoyance:

Sixty adjectives that are in common use for describing people . were given to each of 1300 raters. Each rater was asked to think of a person whom he knew well and to underline every adjective that he might use in a conversational description of that person. . . the . . . correlation . . coefficients for the sixty personality traits were then analyzed by means of multiple factor methods and we found that five [italics added] factors are sufficient to account for the coefficients.

It is of considerable psychological interest to know that the whole list of sixty adjectives can be accounted for by postulating only five independent common factors. . . . we did not foresee that the list could be accounted for by as few . . . factors. This fact leads us to surmise that the scientific description of personality may not be quite so hopelessly complex as it is sometimes thought to be [italics added]. (Thurstone, 1934, pp. 12-14)

\section{The Big Five}

Curiously, Thurstone never followed up his early analysis of these 60 adjectives and instead elected to reanalyze the questionnaire scales developed by Guilford. Oblique rotations of 13 Guilford scales (Thurstone, 1951) led to the development of the seven factors in the Thurstone Temperament Schedule (Thurstone, 1953), two of whose scales intercorrelated over .70. Thurstone's devotion to oblique rotations in factor analysis was mirrored by Raymond B. Cattell, who began his personality explorations with a perusal of the approximately 4,500 trait-descriptive terms included in the Allport and Odbert (1936) compendium. Cattell (1943) used this trait list as a starting point, eventually developing a set of 35 highly complex bipolar variables, each pole of which included a composite set of adjectives and phrases. These variables were then used in various studies, in each of which the correlations among the

Lewis R. Goldberg is at the Department of Psychology, University of Oregon and at the Oregon Research Institute.

This article was a keynote address to the Sixth European Conference on Personality, sponsored by the European Association of Personality Psychology on June 16-19, 1992, in Groningen, The Netherlands. Work on this address was supported by Grant MH-39077 from the National Institute of Mental Health.

I am much indebted to Paul T. Costa, Jr., John M. Digman, Oliver P. John, Robert R. McCrae, Warren T. Norman, Dean Peabody, Gerard Saucier, Auke Tellegen, and Jerry S. Wiggins for their many thoughtful suggestions.

Correspondence concerning this article should be addressed to Lewis R. Goldberg, Oregon Research Institute, 1899 Willamette Street, Eugene, OR 97401 . Electronic mail may be sent to lewg@ori.org. 
variables were factored using oblique rotational procedures (e.g., Cattell, 1947).

Cattell has repeatedly claimed to have identified at least a dozen oblique factors. However, when Cattell's variables were later analyzed by others, only five factors have proven to be replicable (e.g., Digman \& TakemotoChock, 1981; Fiske, 1949; Norman, 1963; Smith, 1967; Tupes \& Christal, 1961). Similar five-factor structures based on other sets of variables have been reported by a number of other investigators (e.g., Borgatta, 1964a; Digman \& Inouye, 1986; Goldberg, 1990, 1992; McCrae \& Costa, 1985a, 1987), and these studies have now been reviewed extensively (e.g., Digman, 1990; John, 1990; McCrae \& John, 1992; Wiggins \& Pincus, 1992; Wiggins $\&$ Trapnell, in press).

These Big-Five factors have traditionally been numbered and labeled, Factor I, Surgency (or Extraversion); Factor II, Agreeableness; Factor III, Conscientiousness; Factor IV, Emotional Stability (vs. Neuroticism); and Factor V, Culture. ${ }^{1}$ More recently, Factor $\mathrm{V}$ has been reinterpreted as Intellect (e.g., Digman \& TakemotoChock, 1981; Peabody \& Goldberg, 1989) and as Openness to Experience (e.g., McCrae \& Costa, 1987). Given the strong consensus that has been emerging about the general nature of the Big-Five domains, the disagreement about the specific nature of Factor $V$ is somewhat of a scientific embarrassment.

Although there is some disagreement about the precise nature of these five domains, there is widespread agreement that some aspects of the language of personality description can be organized hierarchically (e.g., Cantor \& Mischel, 1979; Hampson, John, \& Goldberg, 1986). In such a representation, the Big-Five domains are located at the highest level that is still descriptive of behavior, with only general evaluation located at a higher and more abstract level (John, Hampson, \& Goldberg, 1991). When thus viewed hierarchically, it should be clear that proponents of the five-factor model have never intended to reduce the rich tapestry of personality to a mere five traits (e.g., Shweder \& Sullivan, 1990). Rather, they seek to provide a scientifically compelling framework in which to organize the myriad individual differences that characterize humankind.

Indeed, these broad domains incorporate hundreds, if not thousands, of traits: Factor I (Surgency or Extraversion) contrasts such traits as talkativeness, assertiveness, and activity level with traits such as silence, passivity, and reserve; Factor II (Agreeableness or Pleasantness) contrasts traits such as kindness, trust, and warmth with such traits as hostility, selfishness, and distrust; Factor III (Conscientiousness or Dependability) contrasts such traits as organization, thoroughness, and reliability with traits such as carelessness, negligence, and unreliability; Factor IV (Emotional Stability vs. Neuroticism) includes such traits as nervousness, moodiness, and temperamentality; and Factor V (whether labeled as Intellect or Openness to Experience) contrasts such traits as imagination, curiosity, and creativity with traits such as shallowness and imperceptiveness.

\section{From Critic to Proponent}

It might be argued that the hallmark of a compelling structural model is that it is initially disliked, thereby stimulating numerous attempts to replace it with something more attractive-all of which fail. In any case, so it has been with the Big-Five model of perceived personality trait descriptors. Most of the present proponents of the model were once its critics, and some of its present critics contributed to its success. Indeed, as sympathetically articulated by Wiggins and Trapnell (in press), the intellectual "father" of the Big-Five factors, Raymond Cattell, has consistently denied his paternity and has yet to embrace the model.

\section{The Accidental Discoverer (Fiske)}

Whereas Thurstone (1934) found the correct number of broad personality factors, his collection of 60 trait adjectives was too idiosyncratically assembled to have produced today's Big-Five structure. Instead, the honor of first discovery must be accorded to Donald Fiske (1949), who analyzed a set of 22 variables developed by Cattell and found five factors that replicated across samples of self-ratings, observer ratings, and peer ratings. Fiske's labels for his factors, like those proposed by subsequent investigators, were never perfectly successful attempts to capture the prototypical content of these broad domains: Confident Self-Expression (I), Social Adaptability (II), Conformity (III), Emotional Control (IV), and Inquiring Intellect (V). Like Thurstone before him, however, Fiske did not follow up his initial findings. Indeed, these early histories read like that of Leif Erikson, who made one voyage of discovery, found a continent, but never returned.

\section{The True Fathers (Tupes and Christal)}

To the extent that anyone other than Cattell deserves the real credit for initiating this complex saga, that honor belongs to Tupes and Christal $(1958,1961)$, who analyzed the findings from a number of studies that used sets of variables developed by Cattell (including Fiske, 1949) and found five replicable factors. Their classic 1961 Air Force technical report has now been reprinted (Tupes \& Christal, 1992), along with an appreciatory editorial by McCrae (1992) and a historical introduction by Christal (1992). In the latter, Christal described the remarkable series of U.S. Air Force studies carried out between 1954 and 1961, including investigations of the long-term predictive valid-

\footnotetext{
${ }^{1}$ As was pointed out by Peabody and Goldberg (1989), the interpretation of Factor $\mathrm{V}$ as Culture arose from a historical accident: Although Cattell had initially constructed a subset of variables relating to Intellect, in the seminal studies of Cattell (1947) he omitted all of those variables in favor of an intelligence test. In turn, this test was omitted from his later studies, leaving no direct representation of most Intellect variables. In their absence, Factor $\mathrm{V}$ was called Culture by Tupes and Christal (1961) and some later investigators. However, when variables related to Intellect were reintroduced (e.g., Goldberg, 1990), it became clear that Intellect was the more appropriate label for the fifth broad factor.
} 
ity of peer ratings, a study of the effect of length of acquaintance on the accuracy of such ratings, a comparison of the factor structures derived from variables presented in three different response formats, and-of course-the seminal comparisons of factor structures across diverse samples.

\section{Other Early Explorers (Borgatta and Smith)}

Borgatta (1964a, 1964b) and Smith (1967, 1969) both reacted to the work of Tupes and Christal $(1958,1961)$ with their own independent studies and found much the same five-factor structure. Borgatta (1964a) compared the structures derived from self-ratings with those from peer rankings and peer ratings in two samples and found five robust factors, which he labeled Assertiveness (I), Likability (II), Responsibility (III), Emotionality (IV), and Intelligence (V). Smith (1967) compared the structures derived from three large samples $(N=583,521$, and 324) and found five robust factors, which he labeled Extraversion (I), Agreeableness (II), Strength of Character (III), Emotionality (IV), and Refinement (V); moreover, Smith found that scores derived from the Strength of Character factor correlated .43 with college grades. In a later peernomination study, Smith (1969) recovered Factors I-IV in male and female samples at both the junior high school and high school levels; moreover, he found high correlations with smoking status, smoking being negatively related to Factors II (Agreeableness) and III (Strength of Character), and positively related to Factor I (Extraversion). Neither investigator, however, seems to have carried out any systematic follow-up research, and their role in the history of the Big-Five factors is now typically relegated to a footnote.

\section{The First Serious Critic (Norman)}

Warren Norman, often erroneously labeled the father of the Big-Five structure, spent much of his early research career as a skeptic. Paradoxically, although his importance in the history of the five-factor model is universally acknowledged, his refusal to become a true believer has typically been overlooked. Yet, after his seminal studies confirming the five-factor model with a selected set of Cattell variables (Norman, 1963), he instituted an extensive research program aimed at replacing that model with a more comprehensive one. He began by expanding the corpus of English personality terms assembled by Allport and Odbert (1936), then classifying the terms in the expanded pool into such categories as states, traits, and roles, and finally collecting normative information about some 2,800 trait-descriptive terms (Norman, 1967). Norman was convinced that because of the inevitable computational and other technical limitations of research in the 1930 s and 1940s, Cattell's variables left much to be desired, and therefore that studies using a representative subset of the total English personality-trait lexicon would uncover dimensions beyond the Big Five. Although Norman himself never tested this appealing conjecture, others did (e.g., Goldberg, 1990), and it has proven to be wrong.

\section{The Second Serious Critic (Digman)}

The first computer was coming to the University of Hawaii, and John Digman (an experimental psychologist with no interest in either personality or developmental psychology) set out to learn to program it. As an initial data set to be used to test his ability to program the new machine, Digman decided to try to replicate the child personality factors obtained by Cattell and Coan (1957), inasmuch as he had easy access to teacher ratings at $\mathrm{Ha}$ waii's University Laboratory School. Using the Cattell variables, Digman believed he had found eight oblique factors, some of which differed from those found by Cattell and Coan. ${ }^{2}$ Intrigued by the discrepant findings, Digman (1965) conducted a second teacher-rating study, adding new variables to the original set. Some of Digman's 10 new oblique factors matched neither those from Cattell and Coan nor those from his own first study (Digman, 1963). In an attempt to make sense of these dissonant findings, Digman reanalyzed the data from a number of previous studies of teachers' ratings of children and concluded that 7 oblique factors were robust across the samples (Digman, 1972). In further studies, using different sets of variables, Digman became convinced that there were at least 10 oblique factors of child personality (and perhaps more at the adult level), a view he espoused as recently as 1977.

In the spring of 1978, however, Digman was to teach a course in factor analysis, for which he obtained a number of correlation matrices from classic studies of abilities and personality traits, including those previously analyzed by Tupes and Christal (1961) and by Norman (1963). Before providing them to his students for reanalysis, however, he checked them carefully and found clerical errors in the matrices of two of Cattell's studies. More importantly, he discovered that when six or more factors were rotated from the various matrices, the factors did not correspond, whereas when five factors were rotated, there was striking interstudy correspondence (Digman \& Takemoto-Chock, 1981). Having set out to prove the correctness of a 10-factor model, Digman regretfully became convinced of the robustness of the Big Five. Later teacherrating research by Digman and Inouye (1986) again obtained the Big-Five factors, now with a revised set of child personality variables.

\section{More Recent Critics (Peabody and Goldberg)}

Like Cattell, both Norman and Digman had initially assumed that the dimensionality of phenotypic personality traits was quite large-certainly larger than five. The social psychologist Dean Peabody, on the other hand, had used trait-descriptive adjectives in a series of trait-inference

${ }^{2}$ An interesting historical footnote: Digman presented these findings at a meeting attended by Cattell, who requested a copy of Digman's correlations. Without notifying Digman, Cattell then re-factored these correlations, rotated 12 oblique factors (which he claimed replicated his own), and published his solution before Digman had submitted his own report for publication (Digman, 1963). Indeed, Digman only discovered Cattell's (1963) article when he was sent a reprint. 
studies, in each of which he uncovered only three broad dimensions. Peabody's ideas and procedures were ingenious: Using a dictionary as a starting place, Peabody (1967) concocted various sets of four terms, so that within each set the descriptive and evaluative aspects of trait meanings were systematically unconfounded. For example, one set of four included the traits generous, thrifty, extravagant, and stingy - the first two traits being desirable and the last two undesirable, the first and third referring to loose features and the second and fourth to tight features descriptively. Subjects made trait inferences within each set of four traits (e.g., If one is generous, how likely is one to be thrifty [same evaluative valence but opposite as descriptively] as compared with extravagant [opposite valence but similar descriptively]?).

In a series of factor analyses of subjects' trait inferences across various sets of traits, Peabody $(1967,1970$, 1978,1984 ) uncovered a dimension of general evaluation, plus two descriptive dimensions, which he labeled assertiveness and tight versus loose (impulse control versus expressiveness). In other studies, Peabody (1968, 1985) applied this model to national characteristics, finding widespread agreement on the descriptive features associated with a particular nationality, but disagreement on the evaluations (e.g., We are thrifty [generous], whereas they are stingy [extravagant]).

Although Peabody's three-factor structure had little impact on the general field of personality structure, it had a profound impact on my own thinking. Both Peabody and Norman were among my closest professional colleagues, and I followed their divergent paths with growing consternation. Peabody appeared to become increasingly wedded to his three-factor model, whereas Norman (and later Digman) were convincing many of us that there must be at least five orthogonal trait dimensions. How was one to reconcile these two structural representations? On the one hand, one could simply disregard Peabody's threefactor model in favor of the more inclusive five-factor structure. On the other hand, to my scientific tastes, the Peabody model was elegant and beautiful, whereas the five-factor structure was an aesthetic nightmare: All of the Big-Five factors but the first (Surgency) were highly related to evaluation, and the dimensions themselves had little appeal to me. In contrast, the Peabody model isolated general evaluation as an important dimension of personality perception (which seemed logically compelling), thereby assuring that the remaining dimensions would be evaluation free (which seemed desirable). Moreover, although Peabody has forcefully and consistently denied any similarities between his three factors and the three E-P-A (evaluation, potency, and activity) dimensions of affective meaning discovered in the semantic-differential studies of Osgood, Suci, and Tannenbaum (1957), I was far from convinced. General evaluation is identical in both representations, whereas potency and activity in the Osgood model share important features with Peabody's dimensions of assertiveness and impulse expression. I found these theoretical links intriguing.
In my early work (e.g., Goldberg, 1982), I championed the Peabody model over the Big Five. I expanded on the general idea behind Peabody's sets of four traits to develop clusters of quasi-synonyms and quasi-antonyms grouped into tables we called Peabody plots, in which descriptively similar trait adjectives were listed on the right-hand side of a page, all their antonyms were listed in the left-hand side, and all terms of both types were ordered vertically by their evaluations (indexed by their mean social desirability values from Norman, 1967). Using a variety of different sets of terms, I produced nine rounds of taxonomies of trait-descriptive adjectives (Goldberg, 1982), as well as a taxonomy of trait-descriptive nouns (Goldberg, 1980a).

However, at the same time as I was developing these essentially armchair taxonomies, I was administering large sets of trait-descriptive adjectives to samples of subjects for self-ratings, peer ratings, or both ("external" data) and administering smaller subsets of trait adjectives to other samples for ratings of semantic similarity ("internal" data). During the decade roughly from 1975 to 1985 , I was continuously carrying out analyses of these various data sets in an effort to discover a scientifically compelling taxonomic structure. It was as if I were looking through a glass darkly: In each analysis, I would discover some variant of the Big-Five factors, no two analyses exactly the same, no analysis so different from the rest that I couldn't recognize the hazy outlines of the five domains. For nearly a decade I wandered as if in a fog, never certain how to reconcile the differences obtained from analysis to analysis.

During all of that period I kept searching for a shorthand notational system for labeling variants of the Big Five-something akin to the names of classic chess positions-so that for each analysis I would have a way to refer to its particular factor locations. Ultimately, I wanted to link each of the particular Big-Five variants I had been finding with characteristics of the data-such as the type of item pool, the nature of the subject sample, the use of unipolar as compared with bipolar variables, and the kind of data-analytic procedure. In the absence of such a notational system, I published none of the findings from my structural analyses, but continued to collect additional data and reflect on the findings from each new analysis. ${ }^{3}$

These analyses eventually led me away from my infatuation with the three Peabody factors; I couldn't shake the fact that analyses of any reasonably representative pool of common trait adjectives always provided evidence for five broad factors, rather than for three. Peabody, on the other hand, was still not convinced. To resolve our disagreement, Peabody proposed that we mutually agree on a representative set of bipolar trait scales and then that

\footnotetext{
${ }^{3}$ Some of these analyses of my inventories of 566 and 587 adjectives were presented at a Western Psychological Association symposium organized by John Digman (Goldberg, 1980b) and then eventually published in Goldberg (1990), whereas some of the findings from smaller item pools, including both bipolar and unipolar Big-Five factor markers, were published in Goldberg (1992).
} 
we apply that representative set in a variety of samples of external and internal data. The representative set of scales was developed by Peabody (1987), and the findings from our analyses of those scales in seven data sets were reported in Peabody and Goldberg (1989). In that article, we showed that the factor structures derived from external and internal data were quite similar, but not identical, and that they included five (external) or six (internal) orthogonal dimensions. Moreover, we were able to incorporate the three Peabody factors into the Big-Five structure.

What was still unclear to me, however, was how to secure agreement on the exact positioning of the factor axes in this five-dimensional space. In analyses of external data, the simple-structure position as obtained by varimax rotation will inevitably vary somewhat from sample to sample, even when the same variables are analyzed; one probably needs samples of around 1,000 or more to attenuate such intersample perturbations. Moreover, the simple-structure position is affected enormously by the selection of variables, and no increase in sample size can counteract the effect of this important determinant of factor location. In addition, as Peabody and Goldberg (1989) have demonstrated, the simple-structure location will change as a function of the evaluative homogeneity versus heterogeneity of the targets being described (e.g., self-ratings or ratings of friends vs. ratings of both liked and disliked targets). And, as the analyses reported in Goldberg (1992) suggested, factor locations may depend on whether the ratings are obtained using unipolar or bipolar scales.

In a way, this situation is similar to that faced by early cartographers as they struggled to provide maps of the emerging world. Because the earth is a sphere, any set of orthogonal three-dimensional coordinates could be used to map that world with equal precision. And, just as cartographers eventually settled on a standard system with north-south and east-west axes, so personality researchers must settle on a standard set of locations for the Big-Five dimensions. My efforts to develop factor markers (Goldberg, 1992) are meant to be a step in that direction. Ultimately, the field will form a consensus about the "best" factor locations, a consensus that will be influenced by both aesthetic and practical considerations (Briggs, 1992). ${ }^{4}$

\section{The Assimilators (Costa/McCrae and Wiggins)}

At present, one could argue that there are two five-factor models, one developed by McCrae and Costa (1985a, 1987) and operationalized in the NEO Personality Inventory (NEO-PI; Costa \& McCrae, 1985) and the other associated with studies based on the lexical hypothesis and operationalized in the sets of factor markers provided by Norman (1963), Peabody and Goldberg (1989), Goldberg (1990, 1992), John (1989), Trapnell and Wiggins (1990), and Digman and his associates (e.g., Digman, 1989; Digman \& Inouye, 1986). Much is the same in both models: (a) The number of dimensions is identical, namely five; (b) the content of Factor IV is essentially the same, although it is oriented in the opposite direction in the two models and is thus so labeled (Emotional Stability versus Neuroticism); and (c) there is considerable similarity, although not identity, in the content of Factor III (Conscientiousness). On the other hand, at least two of the differences between the models are quite striking: (a) The locations of Factors I and II are systematically rotated so that warmth is a facet of Extraversion in the NEO-PI, whereas it is a facet of Agreeableness in the lexical model; and (b) Factor V is conceived as Openness to Experience in the NEO-PI and as Intellect or Imagination in the lexical model. ${ }^{5}$

These differences stem from the history of the NEOPI, which started out as a questionnaire measure of a three-factor model, including only Neuroticism, Extraversion, and Openness to Experience. Whereas other three-factor theorists, such as Eysenck (1991), have stood firm as proponents of their original representations, Costa and McCrae reacted to the events of the early 1980 s with such remarkable openness to experience that by the end of the decade these investigators had become the world's most prolific and most influential proponents of the fivefactor model. Their startling transformation was initially stimulated by two papers from a Digman-organized symposium at the 1980 Western Psychological Association convention-the first by Digman and Takemoto-Chock (1981) and the second by me (Goldberg, 1980b)-plus two chapters I published at that time (Goldberg, 1981, 1982). As a reaction to those reports, in 1983 Costa and McCrae invited me to visit them in Baltimore, where I presented the findings from my first studies of bipolar factor markers. My efforts to convince them that five orthogonal factors were necessary to account for phenotypic personality differences (Goldberg, 1983) fell on receptive ears; indeed, they had already administered 40 of my factor markers, along with 40 new rating scales of their own, to their longitudinal sample, and we discussed the preliminary findings during my visit. The rest, as they say, is history (e.g., McCrae \& Costa, 1985a, 1987). Two

\footnotetext{
${ }^{4}$ One such quasi-aesthetic consideration has guided my own work. It has long been known that the evaluation, potency, and activity (E-PA) dimensions of Osgood, Suci, and Tannenbaum (1957) are only orthogonal when a heterogeneous set of concepts are rated on a heterogeneous set of bipolar rating scales, and thus the judgments are primarily metaphorical rather than descriptive. Specifically, when the concepts are all real persons, the dimensions of potency and activity tend to fuse into a construct called dynamism by the Osgood team. Surgency (Factor I) in my preferred rotation of the Big-Five structure represents this fusion of assertiveness and activity level, which explains its relative independence of evaluation.

${ }^{5}$ Actually, the differences between the two versions of the five-factor model can be attenuated in the following ways: (a) The trait descriptor warm has been classified in Facet II $+/ \mathrm{I}+$ in some Abridged Big-Fivedimensional Circumplex (AB5C; Hofstee, de Raad, \& Goldberg, 1992) analyses in the lexical model, whereas warmth is considered a $\mathrm{I}+/ \mathrm{II}+$ facet in the McCrae and Costa model, suggesting more agreement when both primary and secondary loadings are considered than when one considers the primary loadings alone. (b) As suggested by Saucier (in press), neither the labels Openness nor Intellect capture well the central cluster of traits that define Factor V; perhaps a more apt label is Imagination for a factor defined by such traits as creativity and curiosity.
} 
of the Big-Five dimensions, Factor II (Agreeableness) and Factor III (Conscientiousness) were grafted onto their original three-scale structure to form their present model.

The prodigious outpouring of reports by McCrae and Costa probably did more to form the modern consensus about personality structure than anything else that occurred during the 1980s. Specifically, they used the NEO-PI scales as a framework for integrating a wide variety of other questionnaire scales, including those developed by Eysenck (McCrae \& Costa, 1985b), Jackson (Costa \& McCrae, 1988a), Spielberger (Costa \& McCrae, 1987), and Wiggins (McCrae \& Costa, 1989b), as well as the scales included in the Minnesota Multiphasic Personality Inventory (Costa, Busch, Zonderman, \& McCrae, 1986) and the Myers-Briggs Type Indicator (McCrae \& Costa, 1989a). For additional reports of this team, including those describing the revised NEO-PI (NEO-PIR), see Costa and McCrae (1988b, 1992, in press); Costa, McCrae, and Dye (1991); and McCrae and Costa (1992). Indeed, so persuasive has been the McCrae and Costa team that some scientists who originally worked in the lexical tradition, such as Oliver John and Jerry Wiggins, have adopted their interpretation of Factor V (Openness rather than Intellect).

During the past decade, Wiggins $(1979,1980,1982)$ had confined most of his empirical research to the Interpersonal Circle, which is based on Factors I and II in the five-factor model, and over the years Wiggins and his students (e.g., Wiggins, Trapnell, \& Phillips, 1988) have devised Interpersonal Adjective Scales to measure the eight octants within this circular structure. One limitation of this strategy is that a substantial number of traits are not captured by the model. In addition, it is difficult to ensure that traits that have been included in the plane that defines the Interpersonal Circle should not more aptly be classified in one of the missing planes. To remedy these problems, Trapnell and Wiggins (1990) have constructed additional scales to measure the other three factors. As a consequence, Wiggins's present scales include multiple measures associated with Factors I and II, plus single measures of Factors III, IV, and V.

\section{The Yet-To-Be-Convinced}

An emerging consensus is not the same as universal agreement; there are those who do not accept the BigFive factor structure. Indeed, the two most famous holdouts, Cattell and Eysenck, share little but their opposition to the five-factor model. Cattell remains convinced that there are far more factors than five, whereas Eysenck is certain that five is too many. Specifically, Eysenck $(1991,1992)$ has argued that Factor II (Agreeableness) and Factor III (Conscientiousness) in the BigFive representation are merely facets of the higher level construct of Psychoticism in his three-factor P-E-N (Psychoticism, Extraversion, Neuroticism) model. Goldberg and Rosolack (in press) have shown that Psychoticism as measured by the P-scale in the Eysenck Personality Questionnaire (EPQ) is a blend of orthogonal Factors II and III. Moreover, the documented un- reliability of the P-scale stems from the fact that its items are rather equally spaced over the $90^{\circ}$ arc between the poles of the two orthogonal factors. Eysenck (in press) argued that Psychoticism is a more viable construct than either Agreeableness or Conscientiousness because scores on his $\mathrm{P}$-scale are significantly related to a wide variety of other variables. Goldberg and Rosolack (in press) noted that any variable, A, that is formed out of two others, $B$ and $C$, will inevitably relate to all variables associated with $B$, with $C$, or with both. A convincing solution to this seemingly intractable controversy merits a Nobel Prize.

Moreover, Eysenck is not alone in his disdain for the Big-Five model. For example, Jack Block has been a consistent supporter of his two-factor model (Ego Control and Ego Resiliency). Whereas Block has clearly been influenced by the five-factor representation, another recent theorist, Robert Cloninger (1987), introduced his dimensions of harm avoidance, novelty seeking, and reward dependence with no acknowledgment of any more comprehensive representation. And, to add to the cacophony, Zuckerman (1992, in press) has introduced his own fivefactor model and Hogan (1986) has provided a six-factor variant of the Big Five.

\section{Some Practical Implications}

Back in the days when we had no personalities (Mischel, 1968), it made no sense to use personality measures in personnel selection. Now that we have regained our personalities, evidence has been accruing about the utility of personality measures as predictors of diverse criteria (e.g., Hough, Eaton, Dunnette, Kamp, \& McCloy, 1990). Recently, both qualitative (e.g., Hogan, 1991; Schmidt \& Ones, 1992) and quantitative (e.g., Barrick \& Mount, 1991; Tett, Jackson, \& Rothstein, 1991) reviews of the literature have concluded that personality measures, when classified within the Big-Five domains, are systematically related to a variety of criteria of job performance. For example, Barrick and Mount concluded that

The results of the present study have implications for both research and practice in personnel selection. From a practitioner's standpoint, the results suggest that if the purpose is to predict job performance based on an individual's personality, then those measures associated with Conscientiousness [Factor III in the five-factor model] are most likely to be valid predictors for all jobs. In fact, it is difficult to conceive of a job in which the traits associated with the Conscientiousness dimension would not contribute to job success [italics added]. (pp. 21-22)

Interestingly, the meta-analytic review of Tett et al. (1991), although clearly confirming that "personality measures have a place in personnel selection research" (p. 732), concluded that personality measures related to Factor II (Agreeableness) in the Big-Five model were most highly related to criteria of job performance. This inconsistency in the findings between two large-scale quantitative reviews of a similar body of literature is befuddling, and signals the need for more precise and differentiated research on personality-performance relations. Indeed, Tett et al. concluded, 
Our optimism [about the promise of personality measures in personnel selection] derives not only from the overall positive findings obtained in the present study, but also from perceived correctable weaknesses in current validation practices. In particular, we believe the full potential of personality traits in personnel selection will be realized only when confirmatory research strategies employing personality-oriented job analysis become the standard practice for determining which traits are relevant to predicting performance on a given job, and when greater attention is directed to the selection of psychometrically sound [and] construct valid personality measures. (p. 732)

Research on the relations between personality traits and job performance is now of absolutely crucial importance for the optimal deployment of human resources. First of all, recent findings demonstrate quite clearly that some personality measures can provide substantial incremental validities over cognitive measures for the prediction of a variety of job-related criteria (McHenry, Hough, Toquam, Hanson, \& Ashworth, 1990). In addition, unlike most cognitive measures, personality scales tend to have little if any differential impact on protected groups, and thus they are less prone to raise discriminatory concerns (Hogan, 1991). Moreover, although there is no doubt that most personality measures can be distorted when subjects are instructed to fake their responses, the admittedly scanty available evidence suggests that the vast majority of genuine job applicants appear to refrain from such response distortion (e.g., Hough et al., 1990); for a review of this literature in a more specific context, see Goldberg, Grenier, Guion, Sechrest, and Wing (1991).

In summary, there is widespread agreement that noncognitive factors are heavily implicated in many, if not most, aspects of job-related performance. Intellectually able individuals falter on the job when their personality traits are not congruent with task requirements. During the decade of the 1990s, research must focus on the development of (a) personality-oriented job analyses, (b) reliable measures of job-related personality traits, and (c) optimal procedures for linking applicants' personality profiles with job requirements. The Big-Five model of personality traits should prove useful as a framework for each of these three problems. In the words of Barrick and Mount (1991),

In order for any field of science to advance, it is necessary to have an accepted classification scheme for accumulating and categorizing empirical findings. We believe that the robustness of the 5-factor model provides a meaningful framework for formulating and testing hypotheses relating individual differences in personality to a wide range of criteria in personnel psychology, especially in the subfields of personnel selection, performance appraisal, and training and development. (p. 23)

Once upon a time, we had no personalities. Is it not exciting to see their return?

\section{REFERENCES}

Allport, G. W., \& Odbert, H. S. (1936). Trait-names: A psycho-lexical study. Psychological Monographs, 47 (1, Whole No. 211).

Barrick, M. R., \& Mount, M. K. (1991). The Big Five personality dimensions and job performance: A meta-analysis. Personnel Psychology, $44,1-26$.
Borgatta, E. F. (1964a). The structure of personality characteristics. Behavioral Science, 9, 8-17.

Borgatta, E. F. (1964b). A very short test of personality: The Behavioral Self-Rating (BSR) Form. Psychological Reports, 14, 275-284.

Briggs, S. R. (1992). Assessing the five-factor model of personality description. Journal of Personality, 60, 253-293.

Cantor, N., \& Mischel, W. (1979). Prototypes in person perception. In L. Berkowitz (Ed.), Advances in experimental social psychology (Vol. 12, pp. 2-52). San Diego, CA: Academic Press.

Cattell, R. B. (1943). The description of personality: Basic traits resolved into clusters. Journal of Abnormal and Social Psychology, 38, 476506.

Cattell, R. B. (1947). Confirmation and clarification of primary personality factors. Psychometrika, 12, 197-220.

Cattell, R. B. (1963). Teachers' personality description of six-year olds: A check on structure. British Journal of Educational Psychology, 33 219-235.

Cattell, R. B., \& Coan, R. W. (1957). Child personality structure as revealed in teachers' ratings. Journal of Clinical Psychology, 13, 315327.

Christal, R. E. (1992). Author's note on "Recurrent personality factors based on trait ratings." Journal of Personality, 60, 221-224.

Cloninger, C. R. (1987). A systematic method for clinical description and classification of personality variants. Archives of General Psychiatry, 44, 573-588.

Costa, P. T., Jr., Busch, C. M., Zonderman, A. B., \& McCrae, R. R. (1986). Correlations of MMPI factor scales with measures of the five factor model of personality. Journal of Personality Assessment, 50 640-650.

Costa, P. T., Jr., \& McCrae, R. R. (1985). The NEO Personality Inventory manual. Odessa, FL: Psychological Assessment Resources.

Costa, P. T., Jr., \& McCrae, R. R. (1987). Personality assessment in psychosomatic medicine: Value of a trait taxonomy. In G. A. Fava \& T. N. Wise (Eds.), Advances in psychosomatic medicine; Vol. 17. Research paradigms in psychosamatic medicine (pp. 71-82). Basel, Switzerland: Karger.

Costa, P, T., Jr., \& McCrae, R. R. (1988a). From catalog to classification: Murray's needs and the five-factor model. Journal of Personality and Social Psychology, 55, 258-265.

Costa, P. T., Jr., \& McCrae, R. R. (1988b). Personality in adulthood: A six-year longitudinal study of self-reports and spouse ratings on the NEO Personality Inventory. Journal of Personality and Social Psychology, 54, 853-863.

Costa, P. T., Jr., \& McCrae, R. R. (1992). Four ways five factors are basic. Personality and Individual Differences, 13, 653-665.

Costa, P. T., Jr., \& McCrae, R. R. (in press). Revised NEO Personality Inventory (NEO-PI-R) and NEO Five-Factor Inventory (NEO-FFI) manual. Odessa, FL: Psychological Assessment Resources.

Costa, P. T., Jr., McCrae, R. R., \& Dye, D. A. (1991). Facet scales for Agreeableness and Conscientiousness: A revision of the NEO Personality Inventory. Personality and Individual Differences, 12, 887-898.

Digman, J. M. (1963). Principal dimensions of child personality as inferred from teachers' judgments. Child Development, 34, 43-60.

Digman, J. M. (1965). Further evidence for a multiple-factor model of child personality. Educational and Psychological Measurement, 25. 787-799.

Digman, J. M. (1972). The structure of child personality as seen in behavior ratings. In R. M. Dreger (Ed.), Multivariate personality research: Contributions to the understanding of personality in honor of Raymond B. Cattell (pp. 587-611). Baton Rouge, LA: Claitor.

Digman, J. M. ( 1989 ). Five robust trait dimensions: Development, stability, and utility. Journal of Personality. 57, 195-214.

Digman, J. M. (1990). Personality structure: Emergence of the five-factor model. In M. R. Rosenzweig \& L. W. Porter (Eds.), Annual review of psychology (Vol. 41, pp. 417-440). Palo Alto, CA: Annual Reviews.

Digman, J. M., \& Inouye, J. (1986). Further specification of the five robust factors of personality. Journal of Personality and Social Psychology, 50, 116-123.

Digman, J. M., \& Takemoto-Chock, N. K. (1981). Factors in the natural language of personality: Re-analysis, comparison, and interpretation of six major studies. Multivariate Behavioral Research, 16, 149-170. 
Eysenck, H. J. (1991). Dimensions of personality: 16, 5, or 3?-Criteria for a taxonomic paradigm. Personality and Individual Differences, $12,773-790$.

Eysenck, H. J. (1992). Four ways five factors are not basic. Personality and Individual Differences, 13, 667-673.

Eysenck, H. J. (in press). The "Big Five" or "Giant 3"? Criteria for a paradigm. In C. F. Halverson, G. A. Kohnstamm, \& R. P. Martin (Eds.), The developing structure of temperament and personality from infancy to adulthood. Hillsdale, NJ: Erlbaum.

Fiske, D. W. (1949). Consistency of the factorial structures of personality ratings from different sources. Journal of Abnormal and Social Psychology, 44, 329-344.

Galton, F. (1884). Measurement of character. Fortnightly Review, 36, $179-185$.

Goldberg, L. R. (1980a). A catalogue of 1,947 nouns that can be used to describe personality and a taxonomy of 1,342 nouns that are typically so used. Unpublished report, Oregon Research Institute.

Goldberg, L. R. (1980b, May). Some ruminations about the structure of individual differences: Developing a common lexicon for the major characteristics of human personality. Symposium presentation at the meeting of the Western Psychological Association, Honolulu.

Goldberg, L. R. (1981). Language and individual differences: The search for universals in personality lexicons. In L. Wheeler (Ed.), Review of personality and social psychology (Vol. 2, pp. 141-165). Beverly Hills, CA: Sage.

Goldberg, L. R. (1982). From Ace to Zombie: Some explorations in the language of personality. In C. D. Spielberger \& J. N. Butcher (Eds.) Advances in personality assessment (Vol. 1, pp. 203-234). Hillsdale, NJ: Erlbaum.

Goldberg, L. R. (1983, June). The magical number five, plus or minus two: Some considerations on the dimensionality of personality de scriptors. Paper presented at a research seminar, Gerontology Research Center, NIA/NIH, Baltimore.

Goldberg, L. R. (1990). An alternative "Description of personality": The Big-Five factor structure. Journal of Personality and Social Psychology, 59, 1216-1229.

Goldberg, L. R. (1992). The development of markers of the Big-Five factor structure. Psychological Assessment, 4, 26-42.

Goldberg, L. R., Grenier, J. R., Guion, R. M., Sechrest, L. B., \& Wing, H. (1991). Questionnaires used in the prediction of trustworthiness in pre-employment selection decisions: An APA Task Force report. Washington, DC: American Psychological Association.

Goldberg, L. R., \& Rosolack, T. K. (in press). Pitting the Big-Five factor structure against its competitors: An empirical comparison with Eysenck's P-E-N model. In C. F. Halverson, G. A. Kohnstamm, \& R. P. Martin (Eds.), The developing structure of temperament and personality from infancy to adulthood. Hillsdale, NJ: Erlbaum.

Hampson, S. E., John, O. P., \& Goldberg, L. R. (1986). Category breadth and hierarchical structure in personality: Studies of asymmetries in judgments of trait implications. Journal of Personality and Social Psychology, 51, 37-54.

Hofstee, W. K. B., de Raad, B., \& Goldberg, L. R. (1992). Integration of the Big-Five and circumplex approaches to trait structure. Journal of Personality and Social Psychology, 63, 146-163.

Hogan, R. (1986). Hogan Personality Inventory manual. Minneapolis, MN: National Computer Systems.

Hogan, R. (1991). Personality and personality measurement. In M. D. Dunnette \& L. M. Hough (Eds.), Handbook of industrial and organizational psychology (2nd ed., Vol. 2, pp. 873-919). Palo Alto, CA: Consulting Psychologists Press.

Hough, L. M., Eaton, N. K., Dunnette, M. D., Kamp, J. D., \& McCloy, R. A. (1990). Criterion-related validities of personality constructs and the effect of response distortion on those validities. Journal of Applied Psychology, 75, 581-595.

John, O. P. (1989). Towards a taxonomy of personality descriptors. In D. M. Buss \& N. Cantor (Eds.), Personality psychology: Recent trends and emerging directions (pp. 261-271). New York: Springer-Verlag.

John, O. P. (1990). The "Big Five" factor taxonomy: Dimensions of personality in the natural language and in questionnaires. In L. A. Pervin (Ed.), Handbook of personality: Theory and research (pp. 66100). New York: Guilford Press.
John, O. P., Hampson, S. E., \& Goldberg, L. R. (1991). The basic level in personality-trait hierarchies: Studies of trait use and accessibility in different contexts. Journal of Personality and Social Psychology, $60,348-361$.

McCrae, R. R. (1992). Editor's introduction to Tupes and Christal. Journal of Personality, 60, 217-219.

McCrae, R. R., \& Costa, P. T., Jr. (1985a). Updating Norman's "adequate taxonomy": Intelligence and personality dimensions in natural language and in questionnaires. Journal of Personality and Social Psychology, 49, 710-721.

McCrae, R. R., \& Costa, P. T., Jr. (1985b). Comparison of EPI and psychoticism scales with measures of the five-factor model of personality. Personality and Individual Differences, 6, 587-597.

McCrae, R. R., \& Costa, P. T., Jr. (1987). Validation of the five-factor model of personality across instruments and observers. Journal of Personality and Social Psychology, 52, 81-90.

McCrae, R. R., \& Costa, P. T., Jr. (1989a). Reinterpreting the MyersBriggs Type Indicator from the perspective of the five-factor model of personality. Journal of Personality, 57, 17-40.

McCrae, R. R., \& Costa, P. T., Jr. (1989b). The structure of interpersonal traits: Wiggins' circumplex and the five-factor model. Journal of Personality and Social Psychology, 56, 586-595.

McCrae, R. R., \& Costa, P. T., Jr. (1992). Discriminant validity of NEOPIR facet scales. Educational and Psychological Measurement, 52 , 229-237.

McCrae, R. R., \& John, O. P. (1992). An introduction to the five-factor model and its applications. Journal of Personality, 60, 175-215.

McHenry, J. J., Hough, L. M., Toquam, J. L., Hanson, M. A., \& Ashworth, S. (1990). Project A validity results: The relationship between predictor and criterion domains. Personnel Psychology, 43, 335-354

Mischel, W. (1968). Personality and assessment. New York: Wiley.

Norman, W. T. (1963). Toward an adequate taxonomy of personality attributes: Replicated factor structure in peer nomination personality ratings. Journal of Abnormal and Social Psychology, 66, 574-583.

Norman, W. T. (1967). 2800 personality trait descriptors: Normative operating characteristics for a university population. Ann Arbor: University of Michigan, Department of Psychology.

Osgood, C. E., Suci, G. J., \& Tannenbaum, P. H. (1957). The measurement of meaning. Urbana: University of Illinois Press.

Peabody, D. (1967). Trait inferences: Evaluative and descriptive aspects. Journal of Personality and Social Psychology Monographs, 7 (Whole No. 644).

Peabody, D. (1968). Group judgments in the Philippines: Evaluative and descriptive aspects. Journal of Personality and Social Psychology, $10,290-300$.

Peabody, D. (1970). Evaluative and descriptive aspects in personality perception: A reappraisal. Journal of Personality and Social Psychology, 16. 639-646.

Peabody, D. (1978). In search of an evaluative factor: Comments on De Boeck. Journal of Personality and Social Psychology, 36, 622-627.

Peabody, D. (1984). Personality dimensions through trait inferences. Journal of Personality and Social Psychology, 46, 384-403.

Peabody, D. (1985). National characteristics. Cambridge, England: Cambridge University Press.

Peabody, D. (1987). Selecting representative trait adjectives. Journal of Personality and Social Psychology, 52, 59-71.

Peabody, D., \& Goldberg, L. R. (1989). Some determinants of factor structures from personality-trait descriptors. Journal of Personality and Social Psychology, 57, 552-567.

Saucier, G. (in press). Openness versus Intellect: Much ado about nothing? European Journal of Personality.

Schmidt, F. L., \& Ones, D. S. (1992). Personnel selection. In M. R. Rosenzweig \& L. W. Porter (Eds.), Annual review of psychology (Vol. 43, pp. 627-670). Palo Alto, CA: Annual Reviews.

Shweder, R. A., \& Sullivan, M. A. (1990). The semiotic subject of cultural psychology. In L. A. Pervin (Ed.), Handbook of personality: Theory and research (pp. 399-416). New York: Guilford Press. 
Smith, G. M. (1967). Usefulness of peer ratings of personality in educational research. Educational and Psychological Measurement, 27, 967-984.

Smith, G. M. (1969). Relations between personality and smoking behavior in pre-adult subjects. Journal of Consulting and Clinical Psychology, 33, 710-715.

Tett, R. P., Jackson, D. N., \& Rothstein, M. (1991). Personality measures as predictors of job performance: A meta-analytic review. Personnel Psychology. 44, 703-742.

Thurstone, L. L. (1934). The vectors of mind. Psychological Review, 41, $1-32$.

Thurstone, L. L. (1951). The dimensions of temperament. Psychometrika, 16, 11-20.

Thurstone, L. L. (1953). Thurstone Temperament Schedule. Chicago: Science Research Associates.

Trapnell, P. D., \& Wiggins, J. S. (1990). Extension of the Interpersonal Adjective Scales to include the Big Five dimensions of personality. Journal of Personality and Social Psychology, 59, 781790.

Tupes, E. C., \& Christal, R. E. (1958). Stability of personality trait rating factors obtained under diverse conditions (USAF WADC Tech. Note No. 58-61). Lackland Air Force Base, TX: U.S. Air Force.

Tupes, E. C., \& Christal, R. E. (1961). Recurrent personality factors based on trait ratings (USAF ASD Tech. Rep. No. 61-97). Lackland Air Force Base, TX: U.S. Air Force.
Tupes, E. C., \& Christal, R. E. (1992). Recurrent personality factors based on trait ratings. Journal of Personality, 60, 225-251.

Wiggins, J. S. (1979). A psychological taxonomy of trait-descriptive terms: The interpersonal domain. Journal of Personality and Social Psychology, 37, 395-412.

Wiggins, J. S. (1980). Circumplex models of interpersonal behavior. In L. Wheeler (Ed.), Review of personality and social psychology (VoI. 1, pp. 265-294). Beverly Hills, CA: Sage.

Wiggins, J. S. (1982). Circumplex models of interpersonal behavior in clinical psychology. In P. S. Kendall \& J. N. Butcher (Eds.), Handbook of research methods in clinical psychology (pp. 183-221). New York: Wiley.

Wiggins, J. S., \& Pincus, A. L. (1992). Personality: Structure and assessment. In M. R. Rosenzweig \& L. W. Porter (Eds.), Annual review of psychology (Vol. 43, pp. 473-504). Palo Alto, CA: Annual Reviews.

Wiggins, J. S., \& Trapnell, P. D. (in press). Personality structure: The return of the Big Five. In S. R. Briggs, R. Hogan, \& W. H. Jones (Eds.), Handbook of personality psychology. San Diego, CA: Academic Press.

Wiggins, J. S., Trapnell, P., \& Phillips, N. (1988). Psychometric and geometric characteristics of the revised Interpersonal Adjective Scales (IAS-R). Multivariate Behavioral Research, 23, 517-530.

Zuckerman, M. (1992). What is a basic factor and which factors are basic? Turtles all the way down. Personality and Individual Differences, 13, 675-681.

Zuckerman, M. (in press). An alternative five factor model for personality. In C. F. Halverson, G. A. Kohnstamm, \& R. P. Martin (Eds.), The developing structure of temperament and personality from infancy to adulthood. Hillsdale, NJ: Erlbaum. 